\title{
Computer Science Courses Using Laptops
}

\section{Gary Hill, Espen Svennevik \& Scott Turner}

To cite this article: Gary Hill, Espen Svennevik \& Scott Turner (2015): Computer Science Courses Using Laptops, Innovation in Teaching and Learning in Information and Computer Sciences, DOI: 10.11120/ital.2014.00011

To link to this article: https://doi.org/10.11120/ital.2014.00011

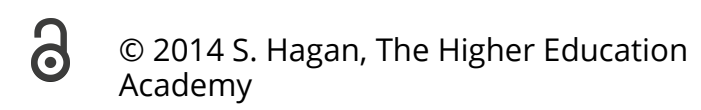
Academy

\section{曲 Published online: 15 Dec 2015.}

Submit your article to this journal

\section{Џll Article views: 1398}

Q View related articles $\smile$

View Crossmark data $₫$ 


\title{
Computer Science Courses Using Laptops
}

\author{
Gary Hill, Espen Svennevik \& Scott Turner \\ Department of Computing \& Immersive Technologies, University of Northampton, UK
}

Corresponding author:

Scott Turner, Department of Computing \& Immersive Technologies, University of Northampton, UK Email: scott.turner@northampton.ac.uk, Phone: +44 (0) 1604893028

\section{Abstract}

Traditionally computer sciences courses have been taught using laboratories full of expensive desktop computers. Although this approach may have been valid in the $80,90 \mathrm{~s}$ and even the early part of this decade, this paper suggests that buying, maintaining and replacing laboratories full of computers is no longer required. This paper raises the issues associated with attempting to use laptops - as thin/thick clients using virtual machines - to deliver the computer science curriculum and offers potential solutions that, in some cases, may make computer science courses at such 'brave' institutions more appealing.

Keywords: laptops, hardware maintenance, save costs, virtual machines, thin clients, dual boot

\section{Introduction}

Traditionally, computer science courses have been taught using laboratories full of expensive desktop computers. However, with a large proportion of computer science students possessing their own laptop/desktop computers (for example $100 \%$ of the University of Virginia (2013) students owned a laptop in 2009) it would make sense to use their resources. This has benefits to the students, as well as the university departments. The University of Northampton Computing \& Immersive Technologies Department will be used as a case study with the view that the findings will be scalable to other 'like' computing departments.

The benefits and issues related to the removal of specialist computing facilities and freeing up resources (Newby 2003) are due to the cost of:

- Purchase: The University of Northampton (UoN) Computing Department has eight specialist computer laboratories with approximately 18 computers in each (total 144). The computers are bought through a preferred Higher Education (HE) supplier at a cost of approximately $£ 750$ per computer. The total cost of $£ 108,000$ is a considerable amount for a small computing department to consider.

- Replacement: It has been stated that a valid reason for considering the move to a laptop department, or even university, should be considered: "as a viable alternative to desktop computer labs at colleges and universities are the rapid advances in technology and the frequent upgrades of costly equipment that make desktop computer labs 
expensive to maintain" (Kontos 2001). Desktop computers go out of date very quickly and the optimum replacement period can be considered to be every three years. To spread the replacement cost, one third of computers at the UoN are replaced each year (approximately $\mathrm{f} 36,000$ ). Again, this could be seen as a considerable and unnecessary drain on the department's budget. There is also the regular need to dispose of three-year-old computers through the appropriate university procedures for writing off and disposing of equipment (although the re-deployment of computers is being considered as a green alternative).

- Set up, maintenance and repair: Technician/specialist support is required to set up, maintain and repair the computers. With 48 new computers being introduced each year and all 144 requiring re-imaging for the start of each academic year. Even ensuring updates/patches are applied and that security protection is in place requires additional time and support.

- Technician support: It is usual for the above set up, maintenance and repair to be carried out by specialist technicians. These technicians are also used to support specialist laboratory sessions on a weekly basis.

- Running: Electricity costs are incurred, not only from the running of the computers, but also the need to then cool/ventilate the rooms to maintain a comfortable environment. Numerous computer labs will have their computers running for longer than required. Ongoing repairs can also add up over the years. The university computers are covered by a three-year warranty, but there is still a cost in time for someone to return the faulty item for repair/replacement and its subsequent re-installation and set up.

- Infrastructure for network/Internet access: The initial cost of installing and maintaining the usual wired network could be expensive. This would lead to an inflexible room layout, when most institutions have started to introduce a wireless option/alternative throughout their buildings. Network usage is fairly limited with most applications running on the client, compared with server-based applications of the past.

- Data back-up: Student data access and storage is an expensive luxury. There is an assumption (and expectation) amongst students that computing departments will safely/ securely look after their data and that they should have an unlimited storage capacity. The cost of storage and maintaining back-ups add another cost to the problem/resource.

- Space: Most universities will be trying to make efficient use of their space, such that laboratories full of wired desktop computers offer one of the least flexible room utilisation to make allowances in the flow and ebb of student recruitment or laboratory usage. Some universities are moving to charging for the space used by departments.

\section{Using laptops}

\section{Introduction}

It has been suggested that: "Mobile wireless technologies are the new frontier for teaching and learning in institutions of higher education" and that the "use in higher education will continue to grow and will become the learning environment of choice" (Kim et al. 2006). Yet eight years later, computer science departments may still be using the same types of computing laboratories, even though the majority of computer science students possess their own laptop/desktop computers. It would make sense to use their resources such that the resourcing of specialist computing facilities could become not only more effective, efficient and economical, but also lead to an enhanced learning experience. 
The above assumption would really need all students to have access to a suitable mobile device and for the current norm of 'on-campus' delivery of practical lab sessions to continue (this in itself could form another discussion in its own right). Students would therefore need access to:

- Laptop and/or external hard disk drive (HDD).

- The Internet.

- Data storage.

- Learning resources.

\section{Laptop and/or external hard disk drive (HDD)}

The idea that an optimal solution to our resource and teaching needs would be a "laptop computer for every student" (Resmer et al. 1995) is not new, but computer science has its own particular constraints, which need to be addressed. There would be a need to determine the minimum specification of the laptop and the resources that would be required on that device. The resources/configuration could range from partitions, operating systems, virtual environments and application software to lecture resources. We are aware of the nightmare scenarios and the need to avoid such reports where "Scores of the leased laptops break down each month, and every other morning, when the entire school has study hall, the network inevitably freezes because of the sheer number of students roaming the Internet instead of getting help from teachers" (Hu 2007).

An incentive to student recruitment, whilst negating the need to purchase laboratory-based computers, could be the introduction of laptops available:

- Free/Incorporated into fees (Orr et al. 2008).

- At a reduced cost through the university or a recognised supplier.

- At a partial cost where the university meets a proportion of the cost.

- Through the leasing of the laptop (Orr et al. 2008).

There are a number of United States HE institutions that have initiated a mandatory laptop programme where laptops are leased or purchased (Carnevale \& Young 2006, Orr et al. 2008).

The student laptops could additionally be set up ready for the start of a student's first year. All required application software, partitions, operating systems and lecture resources could be preloaded.

If students did not wish to avail themselves of the scheme suggested above, there would be a need to be explicit within the course publicity/joining material about the exact computer specification and how to obtain the additional resources. An alternative incentive/solution to obtaining the additional resources could be to supply such students with an external drive set-up in the same way as a laptop. Therefore accommodating/ permitting the option to bring your own laptop (BYOL) would become a feasible alternative.

\section{Internet access}

The need to access the Internet or university intranet would be an essential requirement. This would be due to accessing various resources from Web, file servers and a Virtual Learning Environment (VLE) or course notes. Access could be via the existing wired network or, for greater flexibility, via a wireless network.

\section{Data storage}

In addition to the local storage available to the students (via laptop or external HDD) it would be useful to have file server storage at the university. However, it is becoming more 
common amongst students to use 'cloud' storage options, such as Dropbox (2013), SkyDrive (2013), Windows Live (2013), Box (2013) and GoogleDocs (2013).

Cloud or Internet-based storage options offer a number of advantages to all users, in that files are available from anywhere, with the facility to collaborate/share resources.

\section{Learning resources}

In addition to the learning resources already mentioned i.e. Web and file servers, VLE and preloaded course notes, there would be a preference for the application software to be freely available, or at least easily accessible, to the students. Most university computing departments will normally use freely available open source applications and client/server operating systems and will pay a nominal fee for access to applications and client/server operating systems e.g. DreamSpark (formerly Microsoft Developer Network Academic Alliance (DreamSpark 2013)) and iPhone Operating System Developer University Program (Apple 2013).

\section{Delivering the curriculum}

The authors suggest that a familiar scenario for a computing lecturer could be:

You turn up to give a demonstration to students on your module. Half of the students are on Facebook! You wish you could get rid of Internet Explorer, but you know they need it for the Internet Programming module! What about turning off access to the Internet. Nice idea, but you are demonstrating mixed network programming using Java and C\#. Your C\# demo program loads and you explain the code. You then launch your Java program and nothing happens. You recompile it and still nothing happens. Help! As a last measure you remote desktop to your office machine, hoping no confidential e-mails or inappropriate webpages are open, and manage to do the demo. The students then attempt your exercises and they also can't run the Java example. What is going on? In despair you look through the file system and open the command line. What's that? I don't recognize that PATH set in the environment. What is going on? Hey presto! An old version on Oracle has been installed since your last class and it has an out-dated Java Virtual Machine (VM) and your Java program doesn't work with that VM. You explain this to the students and show how they can explicitly use the correct VM while you silently curse the database lecturer who has arranged for Oracle to be installed. But this is the price you pay for having lab machines to use with $30+$ different modules. Wouldn't it be nice to have your own lab for your module...? Meanwhile one of your students wants you to figure out why his Java installation on his laptop doesn't work!

The previous discussions in this paper have addressed the benefits and issues related to using a laptop or HDD as a tool in computer sciences courses, but it could be argued that this could be a generic solution for any educational programme. What makes computer science different is its reliance on software, whether applications or operating systems, network configuration etc. The laptop could be configured/used in a number of ways to suit the above needs. The configurations would fall into the following categories, using the laptop as follows:

- Thick client.

- Virtual machine(s)/virtual appliance(s).

- Thin client. 


\section{The thick client laptop}

For the laptop to be used as a thick client, software would be installed to mirror what would previously have been installed on the lab machines. This could be installed as a separate partition to ensure the integrity of the installation or to supplement preinstalled software on the original partition. It would also be possible just to install the software necessary for the modules the student was enrolled on to ensure the minimum of potential conflict between software packages. This would require separate images for each academic year and each pathway the student was enrolled on. On our BSc Computing programme, with seven pathways, 21 separate images would be required.

\section{The virtual machine(s) laptop}

On laptops hosting a virtual machine or machines, it would be possible to install a fully preconfigured virtual appliance (VMware 2014) with operating system and application software for all modules on the course (all pathways), a pathway, a given year of the course or a given year of a pathway. It would also be possible to have an individual virtual appliance for each module resulting in no more than six virtual appliances per year per student (our courses have $6 \times 20$ credit modules per year, with the exception of the dissertation module). The advantage of using individual virtual appliances per module would be the ability to use different operating systems, prevent software conflicts and optimisation of the configuration to best suit the delivery of that module. Such virtual appliances could use different operating systems in addition to the essential software. Module leaders would be able to ensure and test such virtual appliances to ensure they are confident in its capability to deliver/support the module. At the University of Northampton, virtual machine images have successfully been used for the last five years in three modules: Computer Networks (level 4), Operating Systems (level 5) and Cyber Security and Cryptography (level 6). The VMware images are installed locally on the computer laboratory clients, with full administrator access with a variety of operating systems and preconfigured application software.

\section{The thin client laptop}

The laptop as a thin client would require access via a remote desktop to a terminal server (real or virtual) or terminal servers. The servers could be, as previously discussed, based on individual modules or a collection of modules. The students would have usernames and passwords to these servers in much the same way they would have had with the laboratory machines. It would also be possible for students to have their own virtual machine/appliance per module to access remotely. With 300 students this would equate to 1800 virtual machines/ appliances, but only a small subset of these would be running, mirroring the modules that are timetabled at any given time for the labs and the students enrolled on them. Assuming that they can only be accessed from the labs, typically no more than 150 will be running at any time.

\section{Cost implications}

The authors are aware of potential cost implications for both hardware and software, in particular for larger more specialised departments where licensing costs may outstrip the costs of hardware.

Cost of client hardware: Most students will have bought their own laptops for running the client software (application or virtual appliance).

Cost of client software: The authors predominantly use open source and free software for teaching software development. Other software tends to be covered by site licences such Microsoft DreamSpark (2013), VMware Workstation (2014), VMware Player (2014). There may be issues with using Microsoft's operating systems for virtual machines but Linux could be an alternative, likewise VirtualBox (2014) could be an alternative to VMware (2014). 
Cost of server hardware: The computing department already has a small cluster of dedicated servers and the cost of additional servers would be considerably less than maintaining and upgrading multiple computer laboratories.

Cost of server software: Existing departmental and campus agreements should cover the operating systems licences for the servers. Any additional cost will also be considerably less than maintaining and upgrading multiple computer laboratories.

In summary, the suggestions above all have their advantages and disadvantages. Issues that would need considering include the complexity of creating and updating numerous images for clients, building, testing and updating virtual appliances and running multiple terminal servers, real or virtualized, and the cost implications.

\section{Discussion}

The purpose of this paper was to stimulate discussion about the need for computer laboratories and their potential drain on dwindling resources. However, with computer science there will always be issues relating to the use of laptops as the sole vehicle for educating undergraduates. Exceptions for this method may include the disciplines of:

- Computer networks e.g. students 'make and break' hardware networks.

- Internet security e.g. specialist testing.

- Specialist development e.g. iPhone programming, where Mac OSX computers are required.

- Access to Web servers/MySOL - use on local laptop.

Another issue for discussion would be the trend of students moving towards the access of resources through other forms with the increase of bring your own device (BYOD) such as smartphones and tablets. BYODs can be a useful complement to laptops. To aid BYOD use and effectiveness there would be a need to make teaching resources accessible/ responsive to the form-factor. This would lead to the development of truly generic mobile/responsive sites, that recognise the screen size of the device accessing the material and serve an appropriate style sheet, instead of a trend to develop mobile micro-sites.

\section{Conclusion}

The experience of the authors (Hill et al. 2011) seems to suggest that the move to laptops as thin/thick clients and the use of a virtual machine(s) is inevitable and that computer science departments are likely to lead the way. The benefits of moving to the use of laptops have been discussed and it is felt that with this solution, despite having some logistical problems of setting up the purchase/loan/support of laptops or facilitating the option to BYOL, the benefits would far outweigh the problems. There have been attempts to formally measure the effectiveness of laptops in higher education (Lauricella \& Kay 2010), which could be adapted and applied to the complex discipline of computer science.

The proposed approach has potential in a variety of subjects other than computer science, but it is the complexity of computer science and the need for different software applications, operating systems and the use of network hardware and Internet security labs etc. that makes this subject area more difficult to solely use a laptop as a thick client. In summary, the authors are not advocating the blanket removal of computer laboratories, but for computer science departments to consider reducing the number of laboratories and to reduce the need to continually buy and dispose of desktop computers, whilst improving and enhancing the learning experience. 


\section{References}

Apple (2013) iOS Developer University Program. Available at http://developer.apple.com/ programs/ios/university/ (accessed 02 September 2013).

Box (2013) Available at www.box.net (accessed 02 September 2013).

Carnevale, D. and Young, J., (2006) The challenges and benefits of requiring students to buy laptops (excerpt). The Chronicle of Higher Education 52 (38), A39.

DreamSpark (2013) Available at https://www.dreamspark.com/ (accessed 02 September 2013).

Dropbox (2013) Available at www.dropbox.com (accessed 02 September 2013).

GoogleDocs (2013) Available at https://docs.google.com (accessed 02 September 2013).

Hill, G., Svennevik, E. and Turner, S. (2011) Green computer science courses! We're going mobile! 7th China-Europe International Symposium on Software Industry Oriented Education, 23-24 May 2011. Northampton, UK: University of Northampton.

Hu, W. (2007) Seeing no progress, some schools drop laptops. Available at http://www.nytimes.com/2007/05/04/education/04laptop.html (accessed 02 September 2013).

Kim, S.H., Mims, C. and Holmes, K.P. (2006) An introduction to current trends and benefits of mobile wireless technology use in higher education. AACE Journal 14 (1), 77-100.

Kontos, G. (2001) The laptop university: a faculty perspective. Educational Technology Review v9 n1.

Lauricella, S. and Kay, R. (2010) Assessing laptop use in higher education classrooms: the laptop effectiveness scale (LES). Australasian Journal of Educational Technology 26 (2), 151-163. Available at http://www.ascilite.org.au/ajet/ajet26/lauricella.html (accessed 02 September 2013).

Newby, G. (2003) Student laptop ownership requirement and centralization of information technology services at a large public university. Annals of Cases on Information Technology 5, 201-213.

Orr, C., Sherony, B. and Steinhaus, C. (2008) Student perceptions of the value of a university laptop program. College Teaching Methods \& Styles Journal 4 (6).

Resmer, M., Oblinger, D. and Mingle, J.R. (1995) Computers for all students: a strategy for universal access to information resources. State Higher Education Executive Office.

SkyDrive (2013) Available at skydrive.live.com (accessed 02 September 2013).

University of Virginia (2013) UVa first-year student computer inventory. Available at http://itc.virginia.edu/students/inventory/compare/ (accessed 02 September 2013).

VirtualBox (2014) Available at https://www.virtualbox.org/ (accessed 23 May 2014).

VMware (2014) Available at https://solutionexchange.vmware.com/store/ virtual_appliances_and_vapps (accessed 13 February 2014).

VMware Player (2014) Available at https://my.vmware.com/web/vmware/ free\#desktop_end_user_computing/vmware_player/6_0 (accessed 23 May 2014).

VMware Workstation (2014) Available at http://www.vmware.com/uk/products/workstation/ (accessed 23 May 2014).

Windows Live (2013) Available at https://home.live.com/ (accessed 02 September 2013). 